\title{
ANALISIS PERANCANGAN SISTEM INFORMASI AKUNTANSI TERHADAP PEMBUATAN PEMBUKUAN AKUNTANSI BERBASIS MICROSOFT EXCEL PADA CV. SURYA ANUGERAH INVESTINDO
}

\author{
Yanna Eka Pratiwi \\ Universitas Merdeka Surabaya \\ yannapratiwiy@gmail.com \\ Buyung Cahya Perdana \\ Universitas Merdeka Surabaya \\ buyungcahyaperdana.gmail.com
}

Didaftarkan: 29 Oktober 2020

Direview : 2 Desember 2020

Diterima : 10 Desember 2020

\begin{abstract}
Seeing the importance of accounting information systems today for organizational progress in helping the implementation of accounting bookkeeping, so it requires a fast and accurate recording process. CV. Surya Anugerah Investindo is a developing company in the field of cobroke property, there is still no accounting information system so that making accounting books is still manual. The weaknesses are that the management or the data process is slow, requires a lot of effort or stages, the information generated has a high enough potential for error. The purpose of this study is to try to design and implement an accounting information system based on Microsoft Excel to produce accounting bookkeepers as needed. Data obtained directly from the company through interviews and documentation. Based on the data obtained, states that the accounting information system CV. Surya Anugerah Investindo has not implemented a computer-based accounting information system. From these weaknesses, researchers provide suggestions for the design of accounting books using a Microsoft Excel-based accounting information system
\end{abstract}

\section{Keywords: Accounting Information Systems, Accounting Computer Systems}

\begin{abstract}
Abstrak
Melihat pentingnya sistem informasi akuntansi pada masa kini terhadap kemajuan organisasi dalam membantu pelaksanaan pembuatan pembukuan
\end{abstract}


akuntansi, sehingga membutuhkan proses pencatatan yang cepat dan akurat. CV. Surya Anugerah Investindo merupakan perusahaan berkembang pada bidang cobroke property masih belum ada sistem informasi akuntansi sehingga dalam pembuatan pembukuan akuntansi masih secara manual. Adapun kelemahan tersebut adalah pengelolaan atau proses datanya lambat, membutuhkan banyak tenaga atau tahapan, informasi yang dihasilkan memiliki potensi kesalahan yang cukup tinggi. Tujuan dari penelitian ini mencoba membuat rancangan dan menerapkan sistem informasi akuntansi berbasis microsoft excel untuk menghasilkan pembukun akuntansi sesuai dengan yang dibutuhkan. Data diperoleh secara langsung dari pihak perusahaan melalui wawancara dan dokumentasi. Berdasarkan data yang diperoleh, menyatakan bahwa sistem informasi akuntansi CV. Surya Anugerah Investindo belum menerapkan sistem informasi akuntansi berbasis komputer. Dari kelemahan tersebut, peneliti memberikan saran untuk perancangan pembukuan akuntansi menggunakan sistem informasi akuntansi berbasis microsoft excel.

\section{Kata kunci: Sistem Informasi Akuntansi, Sistem Komputer Akuntansi}

\section{PENDAHULUAN}

Akuntansi diselenggarakan dalam suatu entitas (bisa berupa organisasi bisnis maupun organisasi nirlaba) (Jusup 2011,5), dengan alasan utama mengapa akuntansi dilaksanakan dalam berbagai organisasi adalah semakin rumit variabel yang dihadapi walaupun didalam perusahaan kecil sekalipun. Keadaan seperti ini menyebabkan para pengambil keputusan semakin bergantung pada data akuntansi. Pesatnya perkembangan teknologi dari waktu ke waktu telah mengubah tatanan masyarakat menuju ke dunia yang serba digital seperti sekarang. Perkembangan teknologi informasi juga kini mulai diterapkan pada proses operasional suatu perusahaan guna memudahkan dalam pengawasan untuk setiap kegiatan di dalamnya. Proses implementasi sistem informasi pada perusahaan biasanya dimulai dengan mengubah sistem yang awalnya tradisional menuju ke sistem baru dimana proses migrasi tersebut dipersiapkan secara matang dengan bantuan model.

Dalam era globalisasi seperti sekarang ini perkembangan teknologi sudah semakin canggih, kebanyakan perusahaan sudah memakai sistem 
dalam penyusunan pembukuan akuntansi. Komputer akuntansi tidak harus menggunakan aplikasi software berbasis program. Microsoft Excel pun dapat digunakan untuk menyusun pembukuan akuntansi yang akurat sehingga dapat digunakan untuk pengambilan keputusan meskipun bukanlah suatu software akuntansi, namun dengan tools yang ada software ini dapat digunakan untuk menyusun pembukuan akuntansi dengan cepat dan mudah. Oleh karena itu penulis mencoba menerapkan dan mengembangkan Microsoft Excel untuk menyusun pembukuan akuntansi. Tentunya diharapkan adanya perbaikan dan kecepatan setelah menggunakan Microsoft Excel.

CV. Surya Anugerah Investindo yang merupakan perusahaan yang sedang berkembang di bidang cobroke property (jasa perantara jual beli rumah). Minimnya sumber daya manusia dengan pencatatan akuntansi secara manual bisa sangat menghambat informasi keuangan yang dibutuhkan pihak manajemen dalam mengambil keputusan, serta memicu munculnya masalah operasional yang dapat menghambat perkembangan perusahaan. Oleh karena itu, perusahaan membutuhkan sistem informasi yang sesuai dengan kebutuhan mengelola dan mengintegrasikan siklus dalam pembuatan pembukuan akuntansi yang akurat bagi perusahaan. Berdasarkan latar belakang diatas, peneliti mengembangkan sistem untuk mempermudah pengelolaan dan pengintegrasian pembuatan pembukuan akuntansi pada perusahaan.

\section{TELAAH LITERATUR DAN PENGEMBANGAN HIPOTESIS}

\section{Sistem Informasi Akuntansi}

Sistem informasi akuntansi merupakan salah satu sumber informasi informal didalam perusahaan. Sisten informasi akuntansi menyediakan informasi yang dibutuhkan oleh manajemen untuk menyelenggarakan perencanaan dan pengendalian atas perusahaan. Seperti yang dikemukakan oleh George H Bodnar yang diterjemahkan oleh Amir Abadi Jusuf $(2003,10)$ 
bahwa sistem informasi akuntansi adalah kumpulan sumber daya, seperti manusia dan peralatan yang dirancang untuk mengubah data keuangan dan lainnya menjadi informasi. Informasi ini dikomunikasikan kepada berbagai pihak pengambil keputusan. Sistem informasi akuntansi mewujudkan perubahan baik secara manual ataupun dengan komputer.

Dari definisi diatas dapat dilihat bahwa tanggung jawab sistem informasi akuntansi pembukuan akuntansi dalam proses manajemen adalah menyiapkan informasi yang diperoleh dari pengumpulan dan pengolahan data transaksi keuangan. Sistem informasi akuntansi pembukuan akuntasi diciptakan, diterapkan serta perlu dikembangkan di perusahaan karena memiliki fungsi-fungsi dan tujuan utama yang sangat penting bagi manajemen perusahaan. Sistem informasi akuntansi pembukuan akuntansi untuk suatu perusahaan akan berbeda dengan perusahaan lain tergantung kebutuhan masing-masing perusahaan.

\section{Siklus Akuntansi}

Siklus akuntansi adalah proses penyediaan lapoan keuangan perusahaan untuk periode waktu. Siklus ini dimulai dari transaksi sampai penyusunan laporan keuangan pada akhir periode. Siklus yang terjadi dalam penyusunan laporan keuangan bernama siklus akuntansi.

\section{METODE PENELITIAN}

Penelitian ini menggunakan metode penelitian deskriptif kualitatif. Salah satu ciri penelitian kualitatif adalah peneliti bertindak sebagai instrumen sekaligus pengumpul data. Instrumen selain manusia (seperti pedoman observasi, pedoman dokumentasi, pedoman wawancara dan sebagainya) dapat pula digunakan, tetapi fungsinya terbatas sebagai pendukung tugas peneliti sebagai instrument kunci. Oleh karena itu dalam penelitian kualitatif 
kehadiran peneliti adalah mutlak karena peneliti harus berinteraksi dengan lingkungan baik manusia dan non manusia yang ada pada lingkup penelitian.

Dalam pengumpulan data pada penelitian ini sangat dibutuhkan informan, yaitu informan yang memahami tentang objek penelitian. Informan yang dipilih harus memiliki kriteria agar informasi yang didapatkan bermanfaat untuk penelitian yang dilakukan. Informan yang peneliti tentukan merupakan orang-orang memahami secara penuh objek penelitian ini.

Penulis menentukan informan penelitian dalam penelitian ini berjumlah tiga orang, yang terbagi menjadi dua orang sebagai informan formal dan satu orang sebagai informan informal. Untuk mengumpulkan data yang diperlukan selama penelitian, penulis melakukan teknik pengumpulan data sebagai berikut : Observasi, Dokumentasi, Wawancara.

\section{HASIL PENELITIAN DAN PEMBAHASAN}

\section{A. Struktur Organisasi CV. Surya Anugerah Investindo}

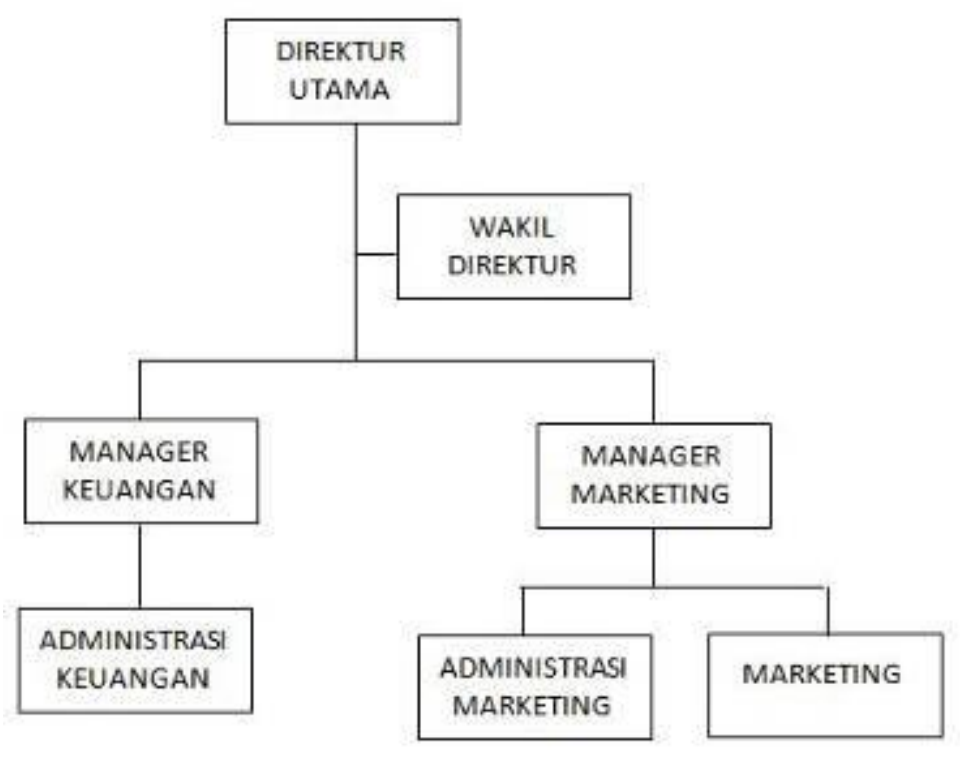

Gambar 1 Struktur Organisasi

Sumber : CV. Surya Anugerah Investindo

Uraian tugas atau job description : 


\section{Manajer Keuangan}

a. Bertanggung jawab atas transaksi arus bank masuk dan keluar.

b. Melakukan koordinasi dengan manajer marketing terkait penjualan.

c. Mengawasi jalannya administrasi keuangan.

2. Manajer Marketing

a. Bertanggung jawab atas omset penjualan perusahaan.

b. Melakukan koordinasi dengan marketing terkait dengan strategi penjualan.

c. Mengawasi marketing dalam transaksi-transaksi penjualan yang dilakukan.

3. Administrasi Keuangan

a. Bertanggung jawab atas transaksi arus kas masuk dan keluar.

b. Melakukan koordinasi dengan administrasi marketing terkait data penjualan dan membuat rekap data penjualan.

c. Membuat perhitungan komisi marketing.

4. Administrasi Marketing

a. Bertanggung jawab atas kelengkapan data penjualan.

b. Melakukan koordinasi dengan marketing terkait rincian data penjualan.

c. Membantu marketing dalam melakukan operasional penjualan (pasang iklan, pesan spanduk, dll)

5. Marketing

a. Bertanggung jawab atas omset penjualan.

B. Sistem akuntansi di CV. Surya Anugerah Investindo

Terdapat dua aktivitas kas, yaitu mutasi transaksi kas kecil dan mutasi transaksi kas bank. Mutasi kas kecil merupakan tanggung jawab bagian administrasi keuangan yaitu meliputi transaksi operasional perusahaan dan 
Pratiwi \& Perdana: Analisis Perancangan Sistem...

transaksi operasional marketing. Sedangkan untuk mutasi kas bank merupakan tanggung jawab manajer keuangan yaitu meliputi pengecekan uang masuk sebelum melakukan pembagian komisi marketing, persetujuan perhitungan komisi marketing dan transfer komisi, dan transaksi operasional perusahaan lainnya.

Proses administrasi transaksi kas kecil dan kas bank yang dilakukan oleh bagian keuangan adalah berikut :

1. Kas Kecil

Bagian administrasi keuangan melakukan tutup kas setiap sore hari, yaitu dengan mengumpulkan nota-nota transaksi pada hari itu juga kemudian menulisnya di buku kas dan menghitung pengeluaran serta menghitung sisa saldo kas apakah sesuai dengan uang sisa kas yang ada. Untuk pemasukan kas kecil didapat dari anggaran biaya yang diajukan setiap hari Jumat ke Manajer Keuangan.

2. Kas Bank

Manajer Keuangan mengadministrasikan transaksi kas bank setiap hari yaitu pengecekan fee yang masuk di kas bank, transfer komisi marketing berdasarkan laporan transaksi, dan transfer pengeluaran operasional perusahaan lainnya. Untuk pencatatan rincian transaksi bank juga dilakukan setiap hari meskipun pencetakan mutasi rekening koran dilakukan satu bulan sekali.

C. Sistem informasi Akuntansi yang diusulkan

Perancangan sistem merupakan tahap inti dalam pokok pembahasan pada penelitian ini. Peneliti menganalisis kebutuhan sistem yang diperlukan untuk mempermudah pekerjaan pengguna sistem tersebut dan menganalisis format apa saja yang diperlukan dalam menyusun laporan keuangan. Berikut ini adalah perbandingan praktek akuntansi yang dijalankan dengan usulan peneliti kepada CV. Surya Anugerah Investindo. 


\section{Tabel 1:}

Perbandingan praktek akuntansi yang dijalankan dan usulan peneliti

No. Kelemahan Sistem Berjalan Usulan

\begin{tabular}{lll}
\hline 1. & cara manual & $\begin{array}{l}\text { Pencatatan akuntansi dibantu } \\
\text { software Microsoft Excel } \\
\text { sebagai alat hitung dan } \\
\text { pembuatan tabel. }\end{array}$ \\
\hline 2. & $\begin{array}{l}\text { Belum membuat laporan } \\
\text { keuangan sesuai standar }\end{array}$ & $\begin{array}{l}\text { Membuat laporan keuangan } \\
\text { sesuai standar }\end{array}$ \\
\hline $\begin{array}{l}\text { Bagian admin mempunyai 3 } \\
\text { fungsi sehingga pengendalian } \\
\text { intern pada bagian } \\
\text { administrasi keuangan masih }\end{array}$ & $\begin{array}{l}\text { Membuat satu bagian agar } \\
\text { tidak double job yaitu bagian } \\
\text { sangat kurang. }\end{array}$ \\
\hline
\end{tabular}

Sumber : Peneliti

D. Struktur Organisasi Yang Diusulkan

Berikut ini adalah struktur organisasi yang diusulkan oleh penulis pada CV. Surya Anugerah Investindo. Penulis hanya mengusulkan bagian akuntansi pada struktur organisasi yang sudah berjalan, ini dilakukan agar tidak terjadi double job pada bagian keuangan sehingga masing-masing bagian dapat lebih fokus pada job description yang ada. Struktur organisasi usulan penulis dapat dilihat pada gambar berikut ini: 


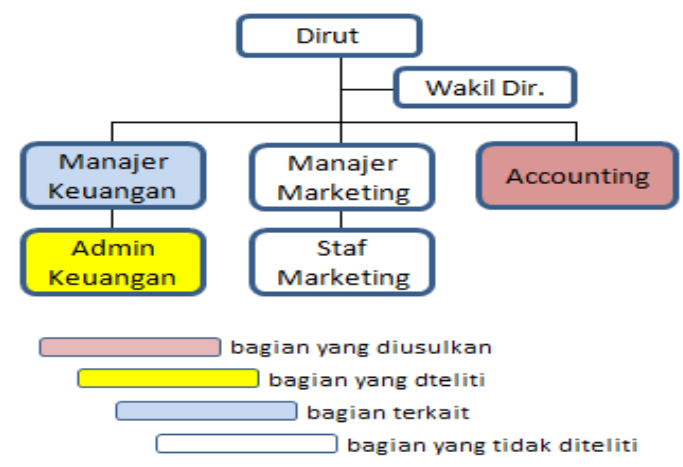

Gambar 2 Usulan Struktur Organisasi

Sumber : Peneliti

\section{Deskripsi Jabatan Yang Diusulkan}

Berikut ini adalah deskripsi jabatan yang diusulkan penulis pada CV. Surya Anugerah Investindo. Deskripsi jabatan usulan ini adalah penjabaran mengenai tugas dan wewenang setiap bagian berdasarkan struktur organisasi yang diusulkan. Penulis mengusulkan salah satu staf administrasi keuangan sebaiknya menjadi bagian akuntansi agar dalam pekerjaan masing-masing bagian lebih fokus terhadap job descriptionyang ada. Adapun penjelasannya adalah sebagai berikut:

Bagian Keuangan

1. Mengatur anggaran masuk dan keluar.

2. Menerima laporan anggaran biaya yang dibutuhkan.

3. Bertanggung jawab terhadap pengelolaan uang.

4. Berhak mengeluarkan uang atas izin pimpinan.

Bagian Akuntansi

1. Melaksanakan pembukuan dan laporan pembukuan secara berkala dan bersumber dari data transaksi kas, bukti penerimaan dan pengeluaran.

2. Mengadministrasikan bukti penerimaan dan pengeluaran.

3. Melaksanakan pencatatan penerimaan dan pengeluaran.

4. Memproses pencatatan ke dalam jurnal.

5. Membuat laporan keuangan secara berkala. 


\section{E. Dokumen Yang Diusulkan}

Perancangan sistem ini menggunakan aplikasi Microsoft Excel. Secara umum dokumen yang akan digunakan sama seperti dokumen manual yang sudah berjalan pada CV. Surya Anugerah Investindo. Di sini user hanya perlu mengisi kode akun agar data dapat saling terhubung. Dokumen sistem informasi akuntansi laporan keuangan yang akan diusulkan adalah:

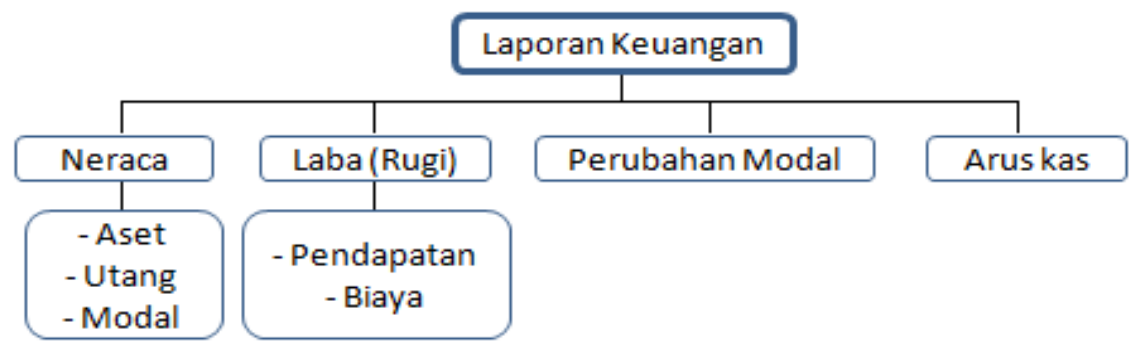

Gambar 3 : Dokumen sistem informasi akuntansi yang diusulkan Sumber : Peneliti

Formulir atau dokumen yang diusulkan dalam sistem informasi akuntansi pada CV. Surya Anugerah Investindo dibandingkan dengan formulir atau dokumen berjalan adalah sebagai berikut:

Tabel 2

Perbedaan Formulir Berjalan dan Usulan

\begin{tabular}{clcl}
\hline No & \multicolumn{1}{c}{$\begin{array}{c}\text { Formulir/Dokumen } \\
\text { Berjalan }\end{array}$} & No & \multicolumn{1}{c}{$\begin{array}{c}\text { Formulir/Dokumen } \\
\text { Usulan }\end{array}$} \\
\hline 1 & Anggaran Biaya & 1 & Anggaran biaya \\
2 & Bukti penerimaan kas & 2 & Bukti penerimaan kas \\
3 & Bukti/nota pengeluaran & 3 & Bukti/nota pengeluaran \\
4 & kas & 4 & kas \\
5 & Buku kas harian & 5 & Buku kas harian \\
& Rekening koran & 6 & Rekening koran \\
& & 7 & Laporan Kas \\
\hline
\end{tabular}



8 Laporan Kas Bank
9 Laporan Neraca
10 Laporan Laba/Rugi
11 Laporan Perubahan Modal
Laporan Arus Kas

Sumber : CV Anugerah Investindo dan Peneliti

\section{F. Desain Sistem Yang Diusulkan}

Tampilan desain menu utama yang digunakan adalah sebagai berikut:

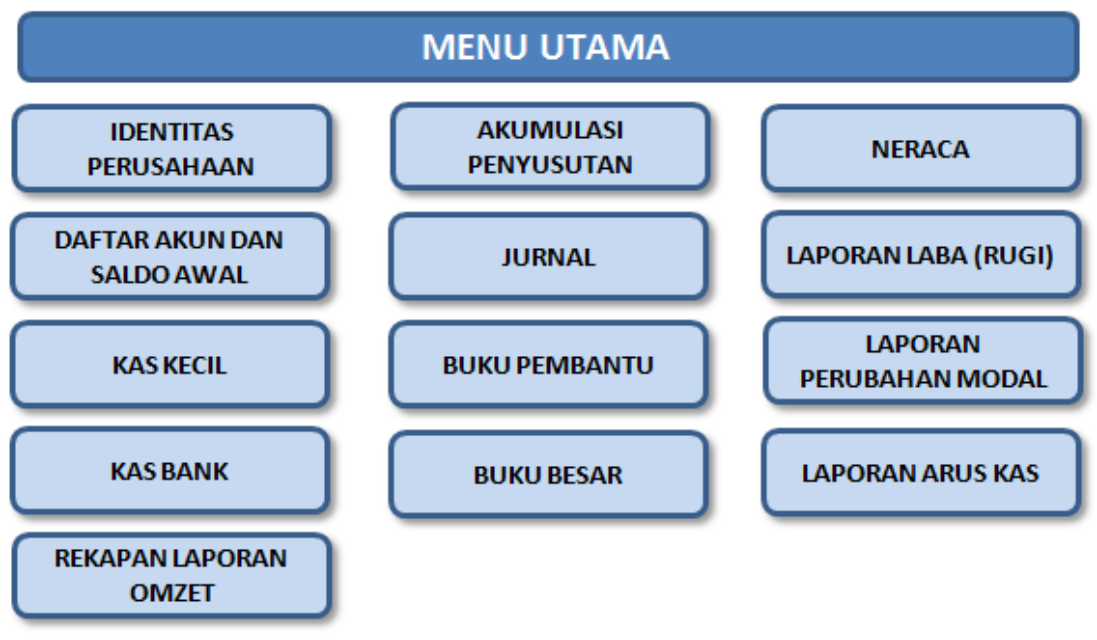

Gambar 4 : Usulan Desai Menu

Sumber : Peneliti

\section{Daftar Akun dan Saldo Awal}

Format yang terdiri dari daftar nomor akun, daftar nama akun, nilai saldo awal tiap akun, keterangan posisi tiap akun, daftar kelompok akun. Format ini adalah kunci dari awal pembuatan laporan keuangan, dimana saldo awal yang dimaksud adalah saldo akhir tiap akun pada periode sebelumnya dan juga sebagai format utama dalam penambahan kode akun dan nama akun apabila terjadi penambahan akun pada bulan pembuatan laporan keuangan tersebut. 


\begin{tabular}{|c|c|c|c|c|}
\hline $\begin{array}{l}\text { XAVIER } \\
\text { MARTH CITRALAND }\end{array}$ & \multicolumn{4}{|l|}{ 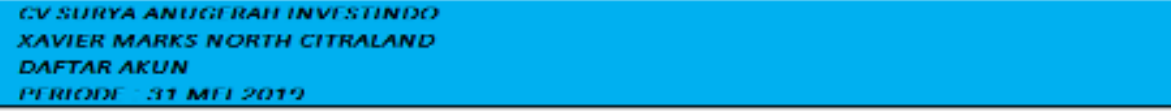 } \\
\hline NOSAKIUN & NAMA AKIJN & S:AIIXS AWAI & 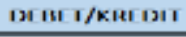 & KIICJMIPCJK \\
\hline 1111 & kas ell Tangan & 560,600 & DEBET & NERACA \\
\hline 1112 & Kas di Bank ( 2583236899) & $111,113,644$ & DEBET & NERACA \\
\hline 1713 & Ras di barik ( $8290 / 54209)$ & $243,496,365$ & DEBSEI & NERACA \\
\hline 1121 & Flutang Fee & & DEBET & NERACA \\
\hline 1122 & Piutang Karyawan & $1,500,000$ & DEBET & NERACA \\
\hline 1723 & Beutarie Marketine & 260,0000 & LEEBELI & NERACA \\
\hline 1211 & Inventarle Kantor & $151,003,000$ & DEBET & NERACA \\
\hline 1212 & Kandaraen & $7,500,000$ & DEBET & NERACA \\
\hline $1: 311$ & Akumulasi Penyusutan Inverntaris & $(14,4236,736)$ & QDEBSE I & NERACA \\
\hline 1312 & Akumulasl Penyusutan Kendaroan & $|3,592,750|$ & DEBET & NERACA \\
\hline 1411 & Sewa Ruko Dibayar Dimuka & $45,000,000$ & DEBET & NERACA \\
\hline 1412 & 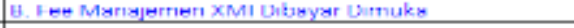 & $53,0000,0000$ & DEBEI & NERACA \\
\hline 1414 & Deposito & $100,000,000$ & DEBET & NERACA \\
\hline $1 A 1=$ & Tramitman Ean & $1=\mathrm{nm}$ nan & neset & MEDAIA \\
\hline
\end{tabular}

Gambar 5 : Format daftarakun

Sumber : Peneliti

\section{Kas Kecil}

Formulir ini dibuat khususnya untuk pemegang kas kecil pada perusahaan yang terdiri dari beberapa kolom yang perlu diinput yaitu tanggal transaksi, dari atau kepada siapa transaksi tersebut, kode akun, nama akun, keterangan transaksi, kolom debet, kolom kredit, kolom saldo.

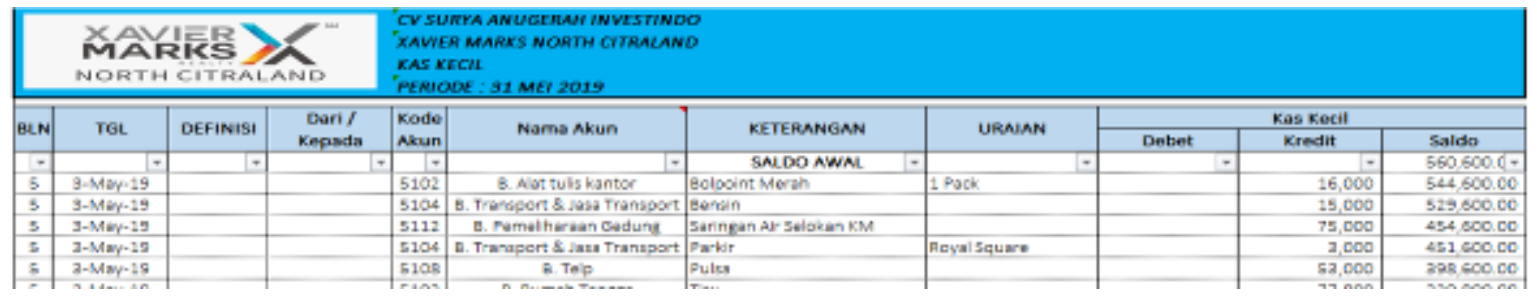

Gambar 6 : Usulan Formulir Kas Kecil

Sumber : Peneliti

Usulan formulir kas kecil pada gambar di atas dapat digunakan oleh pengguna sistem dengan melakukan penginputan data transaksi setiap hari dengan cara sebagai berikut:

1. Mengumpulkan bukti atau nota penerimaan dan pengeluaran kas sesuai tanggal transaksi.

2. Input formulir mulai tanggal transaksi kas. 
Pratiwi \& Perdana: Analisis Perancangan Sistem...

3. Input kode akun transaksi sesuai dengan yang ada pada daftar akun.

4. Untuk kolom nama akun, rumus sebagai berikut:

$$
\text { =IF(F53="", "',,VLOOKUP(F53,Daftar_NamaAkun,2)) }
$$

5. Input keterangan dan uraian transaksi sesuai dengan keterangan pada nota atau bukti penerimaan dan pengeluaran kas.

6. Input kolom debet (penerimaan kas) dan kolom kredit (pengeluaran kas) sesuai bukti kas atau nota.

7. Kolom saldo tidak perlu penginputan karena sudah diberikan rumus yaitu saldo ditambah debet dikurangi kredit dan nilai saldo harus sesuai dengan nilai saldo uang sesungguhnya.

\section{Formulir Kas Bank}

Formulir ini dibuat untuk admin bagian penginputan data bank dimana dari rekening koran disalin dalam format ini yang terdiri dari tanggal transaksi, definisi transaksi, dari atau kepada siapa transaksi tersebut, kode akun, nama akun, keterangan transaksi, uraian transaksi, jenis rekening, kolom debet, kolom kredit, kolom saldo.

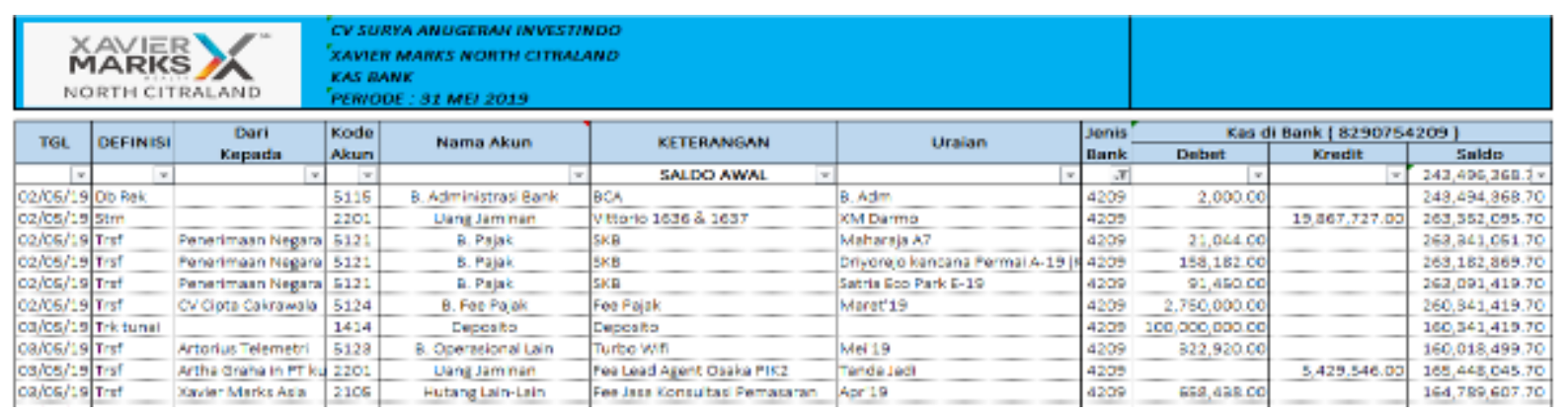

Gambar 7 : Usulan Formulir Kas Bank

Sumber : Peneliti 
Usulan formulir kas bank pada gambar di atas dapat digunakan oleh pengguna sistem dengan melakukan penginputan data transaksi setiap hari dengan cara sebagai berikut:

1. Mengumpulkan bukti atau nota penerimaan dan pengeluaran kas bank, bukti transfer atau pemindahan dana kas bank sesuai tanggal transaksi, serta mutasi rekening koran. Bisa dilakukan setiap hari atau satu minggu sekali melalui aplikasi m-banking.

2. Input formulir mulai tanggal transaksi kas bank sesuai dengan mutasi rekening.

3. Input definisi transaksi sesuai dengan mutasi rekening.

4. Input kode akun transaksi sesuai dengan yang ada pada daftar akun.

5. Untuk kolom nama akun diberikan rumus sebagai berikut:

$$
\text { =IF(F53="", "',,VLOOKUP(F53,Daftar_NamaAkun,2)) }
$$

6. Input keterangan dan uraian transaksi sesuai dengan keterangan pada nota atau bukti penerimaan dan pengeluaran kas yang tertulis di mutasi rekening.

7. Input kolom debet (pengeluaran kas) dan kolom kredit (penerimaan kas) sesuai bukti kas atau nota dan mutasi rekening.

8. Kolom saldo tidak perlu penginputan karena penulis sudah memberikan rumus yaitu saldo ditambah debet dikurangi kredit. Nilai akhir saldo harus sama dengan nilai akhir saldo mutasi rekening.

\section{Akumulasi Penyusutan}

Form ini untuk menghitung nilai penyusutan inventaris dan kendaraan setiap periode bulan akuntansi yang terdiri dari nama inventaris, tahun perolehan, nilai perolehan, nilai lama penyusutan, nilai akumulasi bulan lalu, nilai buku bulan lalu, nilai dasar penyusutan bulan berjalan, biaya penyusutan bulan berjalan, akumulasi penyusutan bulan berjalan, nilai buku bulan 
berjalan. Pada format ini hanya perlu memasukkan nilai akumulasi bulan lalu dan nama inventaris jika ada penambahan asset (inventaris atau kendaraan).

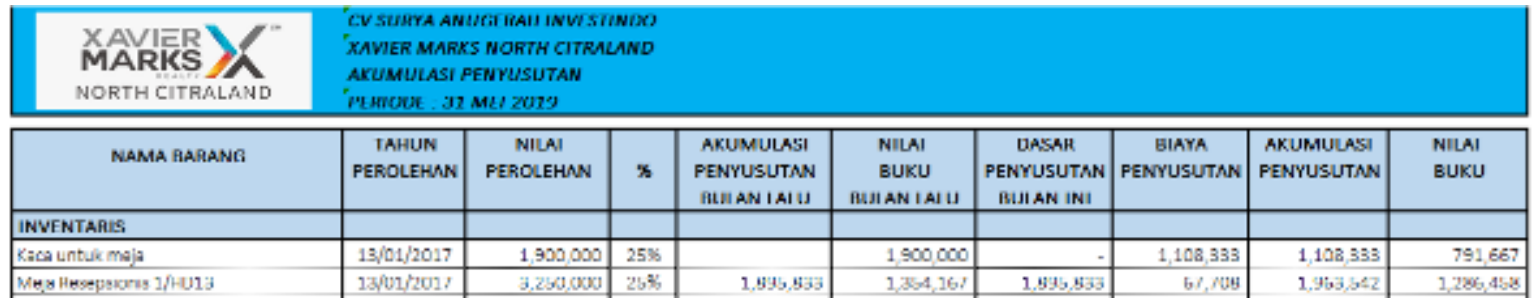

Gambar 8 : Usulan Formulir Akumulasi Penyusutan Sumber : Peneliti

Form akumulasi penyusutan pada gambar di atas menggunakan metode garis lurus yaitu peralatan atau inventaris dengan masa manfaat 4 tahun, nilai penyusutan $25 \%$ tiap tahunnya. Format ini dapat digunakan oleh pengguna sistem dengan cara sebagai berikut:

1. Nama barang, tahun perolehan dan nilai perolehan dapat diinput sesuai dengan nota pembelian.

2. Akumulasi penyusutan tidak perlu ada penginputan karena sudah dirumus yaitu total biaya penyusutan mulai dari awal perolehan inventaris hingga periode akuntansi berjalan.

3. Nilai buku tidak perlu ada penginputan karena sudah dirumus yaitu nilai manfaat atau sama dengan nilai perolehan dikurangi akumulasi penyusutan.

4. Biaya penyusutan tidak perlu ada diisi karena sudah dirumus sesuai dengan metode garis lurus yaitu nilai perolehan dikali 25\% dibagi 12 sehingga dapat diketahui nilai penyusutan tiap bulannya.

\section{Jurnal}

Form ini berisi catatan transaksi-transaksi yang terdiri dari dua bagian yaitu jurnal umum yang berasal dari transaksi kas dan jurnal penyesuaian berasal dari transaksi non kas. 


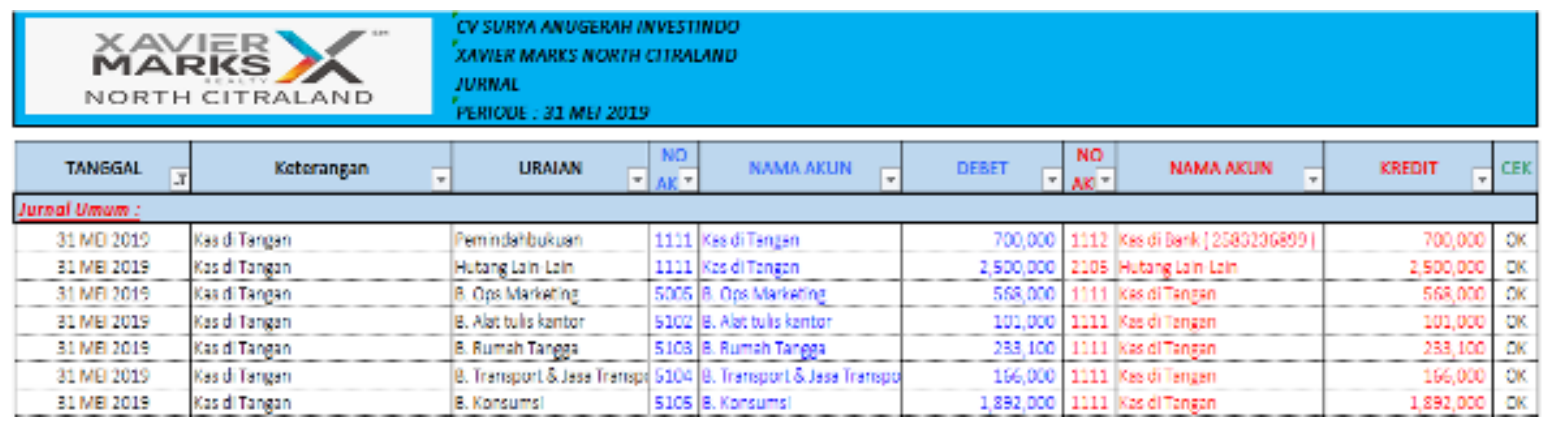

Gambar 9 : Usulan Formulir Jurnal Sumber : Peneliti

Form jurnal memakai bentuk jurnal skontro, user hanya perlu menginput jurnal penyesuaian. Untuk jurnal umum sudah tidak perlu diinput karena jurnal sudah disambungkan rumus dengan form kas kecil dan kas bank. Adapun rumus-rumus yang digunakan adalah sebagai berikut:

$$
\text { =IF(F53="" ,"',VLOOKUP(F53,Daftar_NamaAkun,2)) }
$$

Rumus tersebut menggunakan fungsi logika IF dan fungsi pembacaan tabel VLOOKUP agar pengguna mudah dalam menginput akun. Cara baca rumus tersebut adalah jika kolom nomor akun sama dengan tidak terisi maka nama akun tidak terisi tetapi jika kolom nomor akun terisi maka nama akun akan sesuai pada daftar akun.

Pada jurnal umum tidak perlu diinput nomor akun dan nama akun karena sudah disediakan akun penjurnalannya sesuai jenis transaksi.

$$
\begin{gathered}
\text { =SUMIFS(KasKeluar,AkunKas,E53) } \\
=\text { SUMIFS(4209Kredit,AkunBank,H156) } \\
=\text { SUMIFS(KasMasuk,AkunKas,H8) } \\
=\text { SUMIFS(4209Debet,AkunBank,E172) }
\end{gathered}
$$


Pratiwi \& Perdana: Analisis Perancangan Sistem...

Rumus di atas terletak pada kolom nilai jurnal transaksi debet dan kredit dengan memakai fungsi logika penjumlahan SUMIFS untuk menghitung jumlah nilai dengan akun yang sama kemudian ditotalkan.

\section{Buku Besar}

Form ini dibuat untuk mengetahui detail mutasi transaksi-transaksi setiap akun pada jurnal umum dan jurnal penyesuaian. Tidak perlu ada penginputan, hanya perlu input Nomor Akun maka akan muncul data pada area yang berwarna kuning.

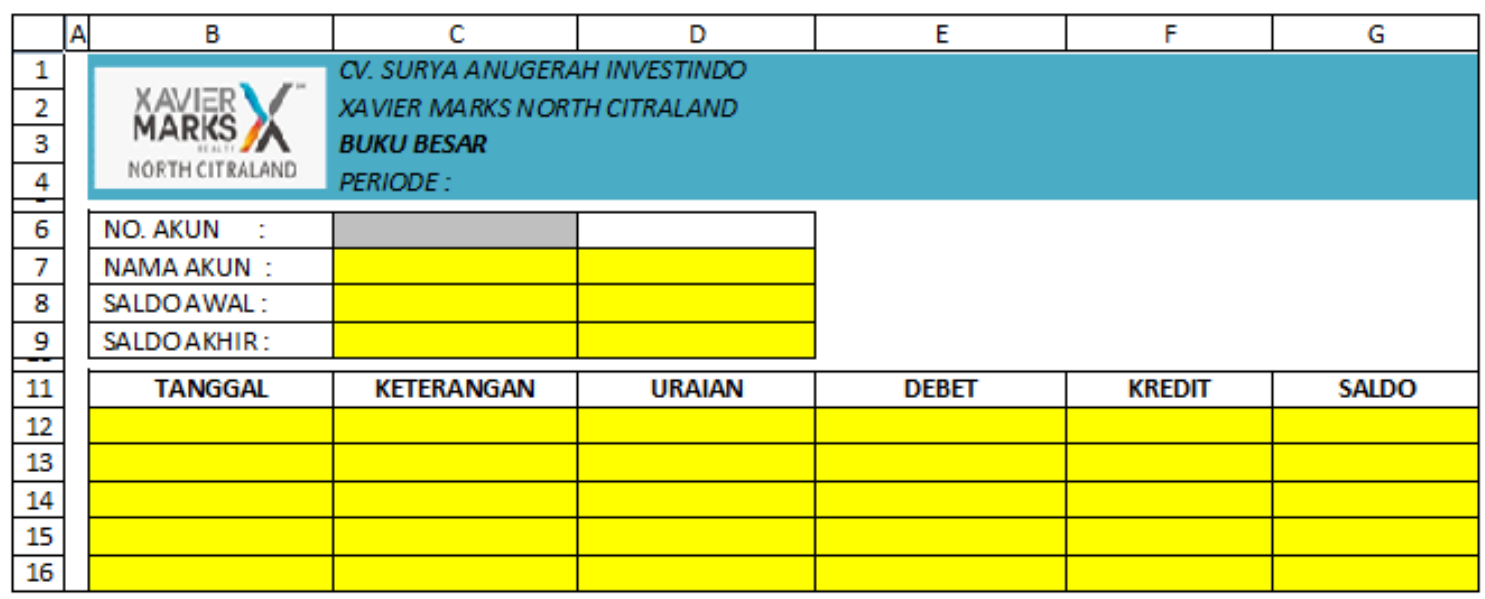

Gambar 10 : Usulan Formulir Buku Besar Sumber : Peneliti

Rumus yang diletakkan pada Nama Akun adalah sebagai berikut:

$$
\text { =VLOOKUP(C6,Daftar_NamaAkun,2) }
$$

Rumus tersebut menggunakan fungsi VLOOKUP agar pengguna mudah dalam memilih akun. Cara baca rumus tersebut adalah jika kolom nomor akun sama dengan nomor akun yang dipilih maka nama akun akan sesuai pada daftar akun.

$$
=\mathrm{IF}\left({ }^{7}\right. \text { '!E56=\$C\$6,'7'!G56,0) }
$$


Rumus tersebut menggunakan fungsi logika IF pada mutasi akun untuk mempermudah pengguna dalam melihat rincian mutasi tiap akun yang dipilih. Cara baca rumus tersebut adalah jika nomor akun yang ada pada formulir jurnal sama dengan nomor akun yang dipilih untuk dilihat di buku besar (cell C6) maka kolom Debet dan Kredit sama dengan kolom jurnal dengan nomor akun yang sama, jika nomor akun yang ada di formulir tidak sama dengan nomor akun yang dipilih untuk dilihat di buku besar maka kolom Debet Kredit tidak terisi.

\section{Neraca}

Form ini berisi laporan posisi keuangan (neraca) yang dibuat dalam bentuk skontro. Pada format ini sudah tidak perlu ada penginputan karena sudah menggunakan rumus secara otomatis bidang warna kuning terisi dan terkait dengan data-data sebelumnya.

\begin{tabular}{|c|c|c|c|c|c|c|c|}
\hline ASET & $\begin{array}{l}\text { SALDO } \\
\text { AWAL }\end{array}$ & $\begin{array}{c}\text { MUTASI } \\
\text { BERJALAN }\end{array}$ & $\begin{array}{l}\text { SALDO } \\
\text { AKHIR }\end{array}$ & KEWAIIBAN DAN EKUITAS & $\begin{array}{l}\text { SALDO } \\
\text { AWAL }\end{array}$ & $\begin{array}{c}\text { MUTASI } \\
\text { BERJALAN }\end{array}$ & $\begin{array}{l}\text { SALDO } \\
\text { AKHIR }\end{array}$ \\
\hline ASET LANCAR & & & & KEWAIIBAN & & & \\
\hline 1111 Kas di tangan & & & & 2101 Hutang gaji & & & \\
\hline 1112 Kas di bank & & & & 2102 Hutang komisi marketing & & & \\
\hline 1113 Kas di bank & & & & 2103 Hutang komisi koordinator & & & \\
\hline 1121 Piutang fee & & & & 2104 Hutang pajak & & & \\
\hline 1122 Piutang karyawan & & & & 2105 Hutang lain-lain & & & \\
\hline \multirow[t]{2}{*}{1123 Piutang marketing } & & & & 2201 Uang jaminan & & & \\
\hline & & & & 2202 Uang titipan & & & \\
\hline \multicolumn{8}{|l|}{ ASET TETAP } \\
\hline 1211 Inventaris kantor & & & & EKUITAS & & & \\
\hline 1212 Kendaraan & & & & 3001 Modal & & & \\
\hline 1311 Akum. Penyusutan Inventaris & & & & 3002 Laba tahun lalu & & & \\
\hline 1312 Akum. Penyusutan Kendaraan & & & & 3003 Laba tahun berjalan & & & \\
\hline \multicolumn{8}{|l|}{ ASET LAINNYA } \\
\hline \multicolumn{8}{|l|}{1411 Sewa ruko bayar di muka } \\
\hline \multicolumn{8}{|l|}{1412 Fee manajemen bayar di muka } \\
\hline \multicolumn{8}{|l|}{1414 Deposito } \\
\hline \multicolumn{8}{|l|}{1415 Komitmen fee } \\
\hline TOTAL ASET & & & & TOTAL KEWAIIBAN DAN EKUITAS & & & \\
\hline
\end{tabular}

Gambar 11 : Usulan Formulir Neraca

Sumber : Peneliti 
Pratiwi \& Perdana: Analisis Perancangan Sistem...

Rumus pada saldo awal neraca menggunakan fungsi logika IF dan fungsi VLOOKUP yang terkait dengan data pada daftar akun dan saldo awal sehingga jika pengguna sudah mengisi daftar akun dan saldo awal maka akan secara otomatis saldo awal neraca juga terisi.

$$
\text { =IF(B24="","",VLOOKUP(B24,Daftar_NamaAkun,4)) }
$$

Pada Mutasi Berjalan (Aset) diletakkan rumus:

$$
\begin{aligned}
= & \text { SUMIF(AkunJurnalDebet,B24,JurnalDebet)- } \\
& \text { SUMIF(AkunJurnalKredit,B24,JurnalKredit) }
\end{aligned}
$$

Pada Mutasi Berjalan (Kewajiban dan Ekuitas) diletakkan rumus:

$$
\begin{aligned}
= & \text { SUMIF(AkunJurnalKredit,H12,JurnalKredit)- } \\
& \text { SUMIF(AkunJurnalDebet,H12,JurnalDebet) }
\end{aligned}
$$

Rumus tersebut menggunakan rumus penjumlahan dan fungsi logika SUMIF dengan cara baca rumusnya adalah penjumlahan nilai pada sisi jurnal debet dengan akun yang ada pada sisi jurnal debet dikurangi penjumlahan nilai pada sisi jurnal kredit (untuk rumus mutasi aktiva) dan penjumalahan nilai sisi jurnal kredit dengan akun yang ada pada sisi jurnal kredit dikurangi nilai penjumlahan nilai pada sisi jurnal debet (untuk rumus mutasi pasiva) sesuai dengan tiap akun neraca.

Untuk saldo akhir neraca menggunakan rumus penjumlahan sederhana yaitu saldo awal ditambah dengan mutasi berjalan. Dengan rangkaian rumus di atas maka form neraca ini akan secara otomatis tersusun.

\section{Laporan Laba/Rugi}

Laporan laba/rugi dibuat dengan maksud menggambarkan hasil operasional suatu perusahaan dalam waktu satu periode akuntansi. Sama halnya dengan form laporan neraca, form laporan laba/rugi ini juga tidak perlu ada penginputan karena sudah menggunakan rumus secara otomatis. 


\begin{tabular}{|c|c|c|c|}
\hline & SALDOAWAL & MUTASI BERIALAN & SALDO AKHIR \\
\hline \multicolumn{4}{|l|}{ PENDAPATAN OPERASIONAL } \\
\hline \multicolumn{4}{|l|}{4101 Fee penjualan property } \\
\hline \multicolumn{4}{|l|}{4102 Fee penjualan KPR } \\
\hline \multicolumn{4}{|l|}{4103 Fee penjualan lead agen } \\
\hline \multicolumn{4}{|l|}{ Total Pendapatan Operasional } \\
\hline \multicolumn{4}{|l|}{5001 Biaya komisi marketing } \\
\hline \multicolumn{4}{|l|}{5002 Biaya komisi koordinator } \\
\hline \multicolumn{4}{|l|}{5003 Biaya jasa konsultan } \\
\hline \multicolumn{4}{|l|}{5004 Biaya ops marketing } \\
\hline \multicolumn{4}{|l|}{ Laba (Rugi) Kotor } \\
\hline \multirow{2}{*}{\multicolumn{4}{|c|}{ BIAYA ADM. DAN UMUM }} \\
\hline & & & \\
\hline \multicolumn{4}{|l|}{5101 Biaya gaji } \\
\hline \multicolumn{4}{|l|}{5102 Biaya ATK } \\
\hline \multicolumn{4}{|l|}{5103 Biaya transport } \\
\hline \multicolumn{4}{|l|}{5104 Biaya listrik } \\
\hline \multicolumn{4}{|l|}{5105 Biaya PDAM } \\
\hline \multirow{2}{*}{\multicolumn{4}{|c|}{5106 Biaya telpon }} \\
\hline \multicolumn{2}{|l|}{5107 Biaya perjalanan dinas } & & \\
\hline \multicolumn{4}{|l|}{5108 Biaya inventaris } \\
\hline \multicolumn{4}{|l|}{5109 Biaya kendaraan } \\
\hline \multirow{2}{*}{\multicolumn{4}{|c|}{5110 Biaya gedung }} \\
\hline 5111 Biaya peny. Inventaris & & & \\
\hline \multicolumn{4}{|l|}{5112 Biaya peny. Kendaraan } \\
\hline \multicolumn{4}{|l|}{5113 Biaya adm bank } \\
\hline \multicolumn{4}{|l|}{5114 Biaya pajak bunga } \\
\hline \multirow{2}{*}{\multicolumn{4}{|c|}{5115 Biaya sewa ruko }} \\
\hline \multicolumn{3}{|l|}{5190 Biaya lain-lain } & \\
\hline \multicolumn{4}{|l|}{ Jumlah Biaya Adm. Dan Umum } \\
\hline \multicolumn{4}{|l|}{ Laba (Rugi) Usaha } \\
\hline PENDAPATAN NON OPERASIONAL & & & \\
\hline 4201 Pendapatan bunga bank & & & \\
\hline 4202 Pendapatan lain-lain & & & \\
\hline Jumlah pendapatan non operasional & & & \\
\hline Laba (Rugi) Bersih & & & \\
\hline
\end{tabular}

Gambar 12 : Usulan Formulir Laba Rugi

Sumber : Peneliti

\section{Laporan Perubahan Ekuitas}

Laporan perubahan ekuitas ini dibuat untuk menggambarkan peningkatan atau penurunan aktiva bersih atau kekayaan selama periode akuntansi berjalan. Format ini sudah dijalankan dengan menggunakan rumus yang saling terkait dengan komponen laporan keuangan lainnya. Pada formulir ini sudah saling terkait rumus dengan formulir neraca sehingga akan secara otomatis akan terisi. 
Pratiwi \& Perdana: Analisis Perancangan Sistem...

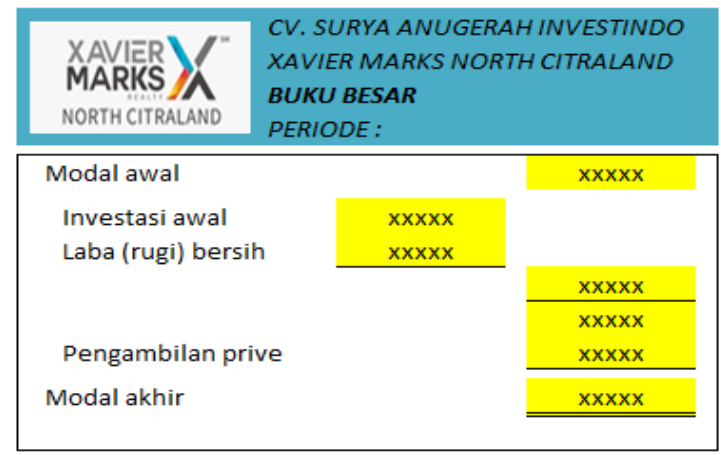

Gambar 13 : Usulan Formulir Laporan Perubahan Ekuitas Sumber : Peneliti

\section{Laporan Arus Kas}

Laporan arus kas atau bisa disebut cashflow ini diambil dari kegiatan operasi, investasi dan juga pendanaan yang melaporkan arus kas masuk atau keluar dari perusahaan pada periode akuntansi tersebut.

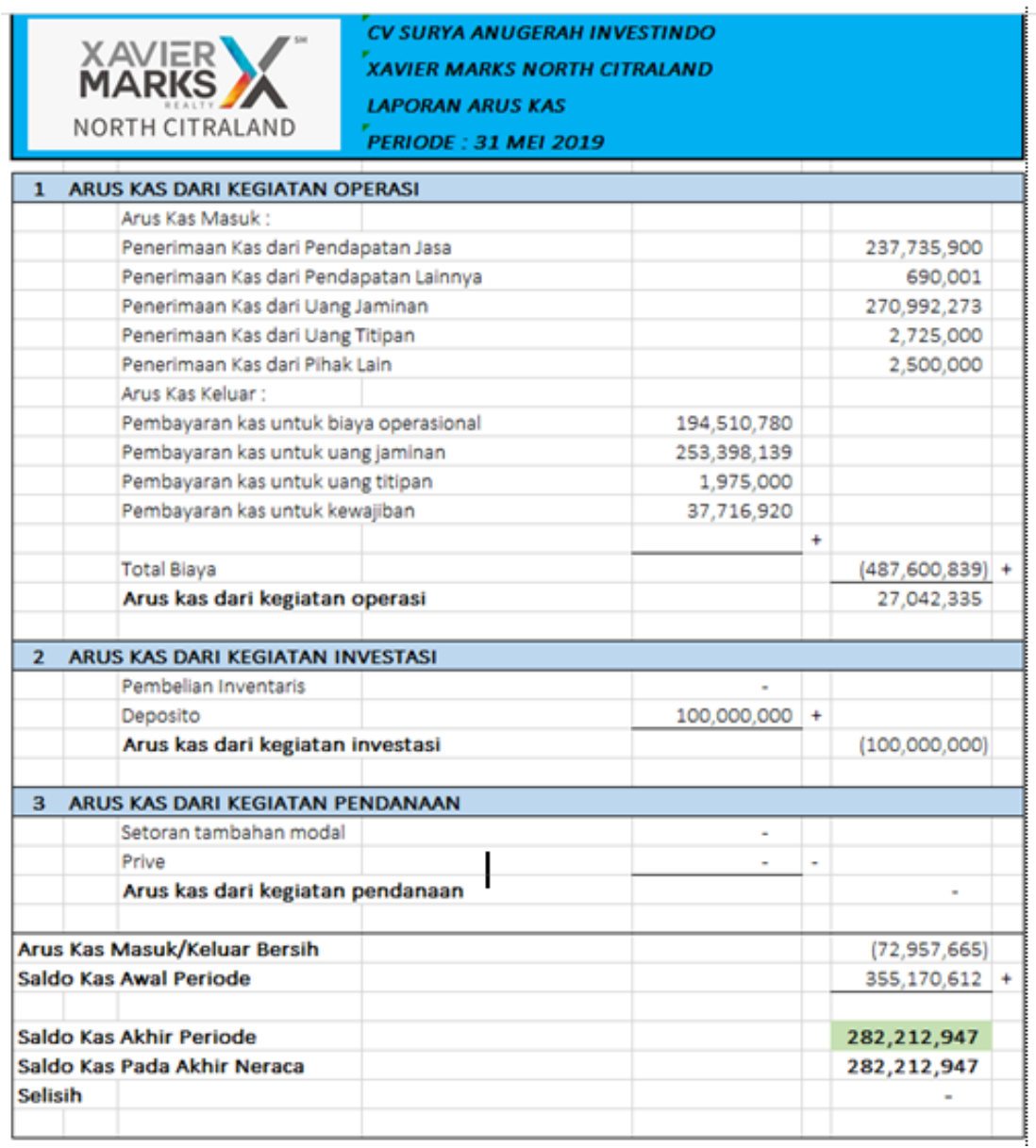


Gambar 14 : Usulan Formulir Laporan Arus Kas

Sumber : Peneliti

\section{Bagan Alir Sistem Informasi Akuntansi Laporan Keuangan Yang Diusulkan}

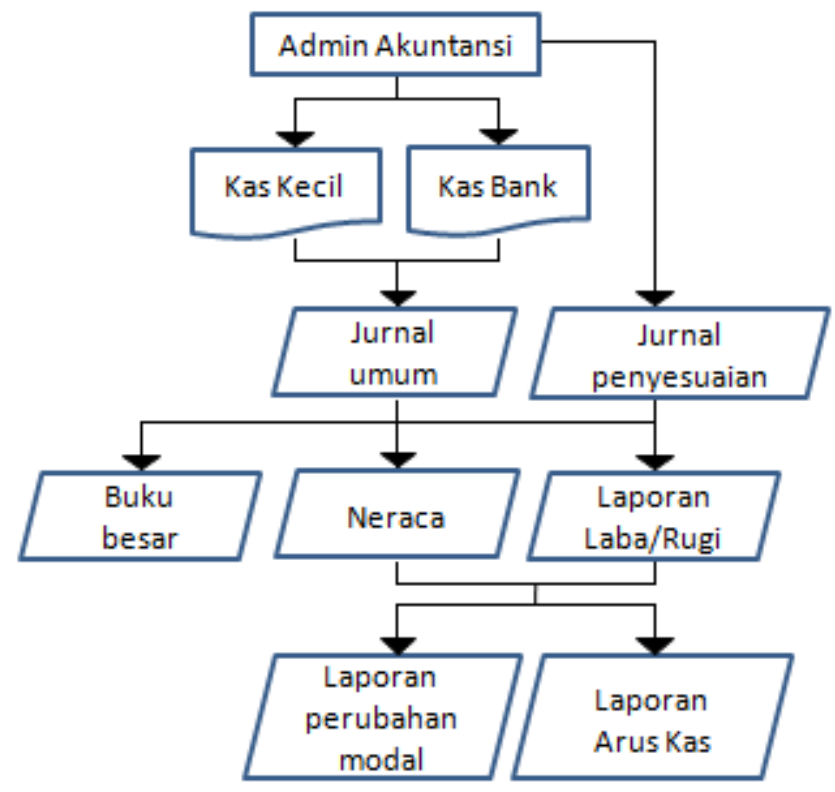

Gambar 15 : Usulan Bagan Alir Sistem Informasi Akuntansi Sumber : Peneliti

Deskripsi bagan alir sistem informasi akuntansi laporan keuangan yang diusulkan adalah sebagai berikut:

1. Bagian admin akuntansi hanya perlu mengisi formulir kas kecil dan kas bank.

2. Dari formulir kas kecil dan kas bank maka jurnal umum akan tersusun secara otomatis, sedangkan untuk jurnal penyesuaian admin akuntansi harus menyusunnya karena jurnal ini merupakan pencatatan transaksi non kas.

3. Dari formulir jurnal umum dan jurnal penyesuaian akan secara otomatis tersusun buku besar, neraca dan laporan laba/rugi. 
Pratiwi \& Perdana: Analisis Perancangan Sistem...

4. Laporan perubahan modal dan laporan arus kas akan tersusun secara otomatis dari neraca dan laba/rugi.

Dari bagan alir yang diuraikan di atas maka admin akuntansi akan dipermudah dalam membuat laporan keuangan dengan menggunakan data atau dokumen yang biasanya digunakan, hanya saja untuk sistem sebelumnya tidak ada laporan keuangan maka dalam usulan sistem baru ini bisa disajikan laporan keuangan yang telah diimplementasikan ke dalam penyusunan laporan keuangan CV. Surya Anugerah Investindo dengan data sampel periode Mei 2019.

\section{SIMPULAN}

CV. Surya Anugerah Investindo sebagai perusahaan yang bergerak di bidang jasa perantara jual beli properti tampak berusaha untuk memahami dan menggunakan sistem informasi akuntansi laporan keuangan ini dalam upaya memperbaiki sistem keuangan yang sudah berjalan. Dengan adanya sistem informasi akuntansi laporan keuangan ini maka perusahaan akan lebih bisa mengendalikan keuangan dengan melihat hasil posisi keuangan pada laporan keuangan yang disusun setiap bulan oleh bagian keuangan.

Kesimpulan dari hasil penelitian ini adalah sebagai berikut:

1. CV. Surya Anugerah Investindo tetap menerapkan aturan-aturan administrasi yang sesuai dengan kebutuhan perusahaan. Hal ini dapat diamati dari dokumen yang digunakan penulis dalam perancangan sistem.

2. Berdasarkan data yang dimiliki oleh CV. Surya Anugerah Investindo, penulis dapat melakukan analisis perancangan sistem informasi akuntansi terhadap laporan keuangan dengan menggunakan Microsoft excel. Analisis dan perancangan sistem informasi akuntansi laporan keuangan yang dibuat dapat berfungsi dengan baik dalam menyajikan 
laporan keuangan berupa laporan neraca, laporan laba/rugi, buku besar, laporan perubahan modal, laporan arus kas sesuai kebutuhan perusahaan.

\section{DAFTAR PUSTAKA}

Jusup, Al Haryono. (2011). Dasar-Dasar Akuntansi Jilid I. Yogyakarta : Sekolah Tinggi IImu Ekonomi YKPN

Purwati, N. dan Noor,H (2016) "Perancangan Sistem Informasi Administrasi Tamu Hotel (Study Kasus Pada Hotel Ganesha Purworejo)", Joural Speed, 8(1), Pp.36-43.

Mulyadi. (2016). Sistem Akuntansi Edisi 4. Jakarta: SalembaEmpat. Rizaluddin, M. dan

Evayani

(2019)"PerancanganSistemInformasiPersediaanBarangMenggunakan Microsoft Access", JurnalIImiahMahasiswaEkonomiAkuntansi (JIMEKA), 4(2), Pp.22-27.

Harahap, Sofyan Safri (2013) "Teori Akuntansi". Edisi Revisi 2011. Jakarta: Radjawali Pers.

StandarAkuntansiKeuanganTahun 2014. IkatanAkuntanIndonesia Indrajit. (2001). Analisa dan Perancangan Sistem Berorientasi Object. Bandung: Informatika.

Jogiyanto H.M (2005). Analisa dan Desain Sistem Informasi: PendekatanTerstrukturTeoridanPraktikAplikasiBisnis, ANDI, Yogyakarta.

Sutarman. (2009). PengantarTeknologiInformasi, Jakarta :BumiAksara. Azhar Susanto. (2013). Sistem Informasi Akuntansi. Bandung: Lingga Jaya.

Mulyadi. (2016). Sistem Akuntansi Edisi 4. Jakarta: Salemba Empat, 1-3. 
Pratiwi \& Perdana: Analisis Perancangan Sistem...

Baridwan, Zaki. 2009. Sistem Akuntansi Penyusunan Prosedur dan Metode. Yogyakarta: YKPN.

Krismiadji. (2015). Sistem Informasi Akuntansi. Yogyakarta: Unit Penerbit.

Kieso E. Donald. 2013. Akuntansi Intermediate. Erlangga Jakarta.

Krismiadji. (2015). Sistem Informasi Akuntansi. Yogyakarta: Unit PenerbitHall. (2007). Sistem Informasi Akuntansi. Buku satu. Jakarta : Salemba Empat.

Abadi Jusuf, Amir. (2011). Auditing Pendekatan Terpadu, Jakarta: Salemba Empat. 